\title{
Improved economic viability of integrated biogas energy and compost production for sustainable palm oil mill management
}

\begin{abstract}
This paper proposes a new approach for integrated technology of biogas energy and compost production for a palm oil mill. This study evaluated the economic viability based on the changes of materials flow and energy balance when a palm oil mill introduces this approach. A palm oil mill processing 54 tonnes fresh fruit bunch (FFB) per hour has the potential to produce $8.2 \mathrm{GWh}$ per year of electricity using biogas captured during anaerobic treatment of palm oil mill effluent (POME). Compost production using shredded empty fruit bunch (EFB) and POME anaerobic sludge obtained from the anaerobic digester is equivalent of 579 tonnes, 151 tonnes and 761 tonnes per year of nitrogen, phosphorus and potassium respectively. The integrated technology is a more attractive solution compared to the case when the palm oil mill installs either biogas energy or compost technology individually. The result of economic analysis suggests that this integrated approach is the most economically effective in comparison to the other two cases. Interestingly, even without Clean Development Mechanism (CDM), the integrated technology can still be economically viable, which can be a good solution for sustainable palm oil industry management in the near future.
\end{abstract}

Keyword: Oil palm biomass; Palm oil mill effluent; Empty fruit bunch; Biogas energy; Compost; Clean development mechanism (CDM) 